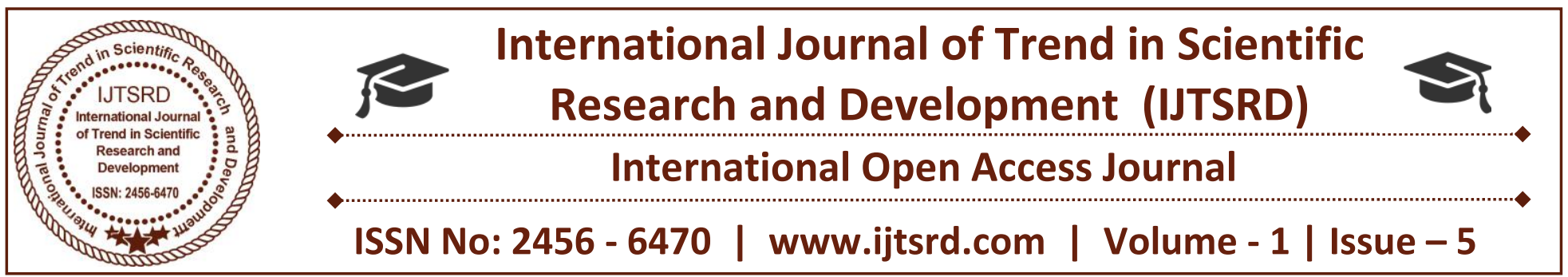

\title{
To Study the Behaviour of Fresh and Hardened Concrete by using Waste Rubber as Partial Replacment of Coarse Aggregates
}

\author{
Taweel Awzal \\ Department of Civil Engineering, \\ Al-falah University, Faridabad, Haryana
}

\author{
Masoom Raza \\ Department of Civil Engineering, \\ Al-falah University, Faridabad, Haryana
}

\begin{abstract}
This report presents a study on the effect of partial replacement of coarse aggregates by rubber tyre aggregates on the property of concrete. Utilizing the waste rubber tyers in the form of aggregates as reinforcement in the concrete solve the problem of disposing the waste and increase the flexural strength of concrete. Different tests were conducted on the concrete with varying percentage of rubber tyre aggregates and comparing those results with normal concrete. Data presented includes workability, compressive strength, split tensile strength, flexure tensile strength and flexibility.
\end{abstract}

This report describes an experimental study on mixing rubber aggregates with concrete at different mixing ratios $(0,5,10$, and 15$) \%$ by weight of coarse aggregates. The tests conducted were workability, compressive strength, split tensile strength, flexure tensile strength. Though there is decrease in compressive strength, workability, split tensile strength, flexural strength and flexibility get increased.

Keywords: Rubber tyer coarse aggregates, utilizing waste rubber

\section{INTRODUCTION}

The management of worn tyres poses a major problem for all third world countries. Also, with the increasing number of vehicles, the industrial development which several countries are currently knowing, and the small percentage of recycled worn tyres (retreaded or used for other purposes) due to the absence of an adequate plan for eliminating this waste, these countries know surely a major environmental problem. The absence of statistics on this subject does not enable us today estimate suitably the mass of worn tyres thrown in nature or burned in public dumpsters. But if we compare these countries with the European Union countries which took this problem in charge, through legislation, recycling companies, re-search; we can say that many countries are postponing the solution to this problem, and that the mass of worn tyres can only be considerable. One of the recommended solutions to solve this environmental problem is to incorporate rubber aggregates resulting from cutting worn tyres in the cement concretes.

\section{OBJECTIVES}

The main objective of the study is to use the waste rubber as a partial replacement of coarse aggregate for the positive variations in the properties of the mix and also its impact on the economic growth of the construction industry and to explore the use of replaced materials. Further, the effect of materials used as admixture is to be determined by testing workability, tensile strength, compressive strength, durability, etc. of cement mortar. These tests will enable a complete characterization and an evaluation of application possibilities. The main objectives of the study are summarized below.

1. The main objective of this study is to investigate the effect of addition of shredded rubber into the Portland cement concrete in three different replacement levels i.e. $5 \%, 10 \%$ and $15 \%$ by mass 
International Journal of Trend in Scientific Research and Development (IJTSRD) ISSN: 2456-6470

of coarse aggregates and evaluate the fresh and hardened rubberized concrete properties.

2. Secondary objective of this experimental study is to investigate the effect of surface treatment of rubber on various properties of rubberized concrete .Two different treatments will be given to the rubber aggregates.

A. Treatment by coating the rubber aggregates with cement paste.

B. Treatment by washing the rubber aggregates with $\mathrm{NaOH}$ solution.

3. To prepare lightweight concrete by using waste rubber as partial replacement of course aggregate.

4. Utilization of waste rubber in the concrete construction sector, hence eliminating the need of land fill disposal of this non bio-degradable waste.

\section{LITERATURE REVIEW}

Various literature reviews covering published research reports, journal articles, and other documents that discussed the utilization of scrap tires in civil engineering applications focusing on rubberized concrete with tyre chips incorporated have been worked out by various researchers.

\section{GINTAUTAS SKRIPKIUNAS, AUDRIUSGRINYS}

[1]: The aim of investigation was to study the deformation properties of Portland cement concrete with rubber waste additive. Concrete mixtures with the same compressive strength as concrete without this additive were tested. Used tyre rubber wastes were crumbed into fraction 0.1 . The rubber additive was used as fine aggregate replacement in concrete mixtures by $3.2 \%$ of aggregates mass. The effect of rubber waste additive on technological properties, air content in fresh concrete, density and deformation properties under the static and dynamic load of concrete was investigated.

\section{AKINWONMI, ADEMOLASAMUEL,} EMMANUEL, SECKLEY, this paper presents a research into the mechanical strength of concrete with shredded tyre and crumb tyre as aggregate replacement. The materials used to make concrete for this experiment are coarse aggregate, cement, sand, shredded tyre, crumb tyre, potable water and Ordinary Portland Cement. A total of fifteen main mixtures were cast as solid bricks with $0 \%$ replacement as control then followed by $5 \%, 7.5 \%, 10 \%, 12.5 \%$, $15 \%, 17.5 \%, 20 \%$ separately for both shred and crumb rubber materials. The compressive tests for the concrete cubes were carried out by applying a constant uniform pressure to the cubes of the concrete blocks until failure occurred. The results of the compressive test show that by replacing the aggregate by $2.5 \%$ shredded tyre, the compressive strength increased by about $8.5 \%$ but at $5 \%$ re-placement and beyond, the compressive strength decreased. For the Crumb tyre aggregates, the compressive strength decreased generally as the percentage replacement increased. Thus, crumb tyre is not advisable to be used as aggregate replacement due to its weak compressive strength. Shredded tyre could be used as replacement of aggregates in concrete production up to $2.5 \%$ replacement in order to help reduce the cost of concrete production arising from the increasing cost of cement, and reduce the volume of waste generated from unused tyres.

PARVEEN, SACHIN DASS, ANKIT SHARMA [3]: The disposal of used tyres is a major environmental problem throughout the world which causes environmental hazards. Crumb rubber is a waste material that is ideal for use in concrete applications. The aim of this study is achieved to use of rubber waste as partial replacement of fine aggregate to produce rubberized concrete in M30 mix. Different partial replacements of crumb rubber $(0,5,10,15$ and $20 \%$ ) by volume of fine aggregate are cast and test for compressive strength, flexural strength, split tensile strength and stress-strain behavior. The results showed that there is a reduction in all type of strength for crumb rubber mixture, but slump values increase as the crumb rubber content increase from $0 \%$ to $20 \%$. Meaning that crumb rubber mixture is more workable compare to normal concrete and also it is useful in making light weight concrete. It is recommended to use the rubberized concrete for non-structural applications.

N. J. AZMI B. S. MOHAMMED, [6]: The test program was carried out to develop information about the mechanical properties of rubberized concretes. A control Portland cement concrete mix (PCC) is designed using American Concrete Institute mix design methods and crumb rubber contents of 10,15 , 20 and $30 \%$ by volume were chosen by partially replacing the fine aggregate with crumb rubber. Totally 15 concrete mixes with three different water cement ratio $(0.41,0.57$ and 0.68$)$ were cast and 
International Journal of Trend in Scientific Research and Development (IJTSRD) ISSN: 2456-6470

tested for compressive strength, splitting tensile strength, flexural strength and modulus elasticity. The results revealed that although there is a reduction in strength for crumb rubber mixture, but slump values increase as the crumb rubber content increase from $0 \%$ to $30 \%$. Means that crumb rubber mixture is more workable compare to normal concrete and can be acceptable to produce crumb rubber concretes. The results also indicated that inclusion crumb rubber in concrete reduced the static modulus elasticity. Although there is a reduction in modulus of elasticity but the de-formability in crumb rubber concrete increased compared to normal concrete.

GANJIAN ET AL [4]: In 2008, they investigated the performance of concrete mixture incorporating $5 \%$, $7.5 \%$ and $10 \%$ tyre rubber by weight as a replacement of aggregate and cement. Two set of concrete mixes were made. In the first set, chipped rubber replaced the coarse aggregate and in the second set, scrap tyre powder replaced cement. The durability and mechanical tests were performed. The result showed that up to $5 \%$ replacement in both sets no major changes occurred in concrete characteristic.

\section{METHODOLOGY}

\subsection{Material Testing}

Following tests were conducted on the materials used.

a) Cement tests:- Consistency test, determination of initial and final setting time, compressive strength test

b) Tests For fine aggregate:-

Tests for sand: - Determination of specific weight, sieve analysis.

c) Tests for coarse aggregates:-

Tests for gravel: - Sieve analysis, crushing test, impact test, abrasion test, water absorption test.

\subsection{Preparation of Samples:}

All samples were prepared in the Concrete Laboratory at Al-falah University during the months of March June, 2017. The samples for compression testing were cubes of size $(15 \mathrm{~cm} \times 15 \mathrm{~cm} \times 15 \mathrm{~cm})$, the Beams of size $(50 \mathrm{~cm} \times 10 \mathrm{~cm} \times 10 \mathrm{~cm})$ were used for flexure testing and the cylinders of size $(10 \mathrm{~cm} \times 20 \mathrm{~cm})$ were used for split tensile strength testing.

\section{$>$ Treatment of rubber:}

Treatment of rubber wastes involves its surface modification to improve the bond between rubber and other aggregates and it was done by soaking rubber particles in $0.1 \mathrm{M}$ solution of $\mathrm{NaOH}$ and in cemented suspension.

\section{NaOH Treatment:}

The scrap tyre rubber aggregates were surface treated with saturated $0.1 \mathrm{~m} \mathrm{NaOH}$ solution for 20 min. When treated with cement paste showed that addition of rubber particles improved toughness and reduced the porosity of the specimens. SEM showed that $\mathrm{NaOH}$ sur-face treated rubber improved the rubber matrix bonding and also increased flexural strength and fracture energy.

\subsection{Concrete Mix Design (Grade M20)}

\section{i) Characteristic Compressive Strength}

Required in the period of 28 days - 20Mpa

Max. Size of aggregate - $20 \mathrm{~mm}$ (angular)

Degree of workability - 0.90

Type of exposure - mild

\section{ii) Test data for materials}

Specific gravity of cement -3.10

Specific gravity of C.A - 2.65

Specific gravity of F.A - 2.65

Target mean strength of concrete

The Target mean strength for

Specified Characteristic cube strength $=20+(1.65$ x 4) $=26.6 \mathrm{MPa}$

Adopt W/C ratio of 0.45

For change in W/C ratio, compacting factor, for sand belonging to zone II following adjustment is required. 
International Journal of Trend in Scientific Research and Development (IJTSRD) ISSN: 2456-6470

Table 4.1 change in $W / C$ ratio

\begin{tabular}{|c|c|c|}
\hline \multirow{2}{*}{$\begin{array}{c}\text { Change in } \\
\text { condition }\end{array}$} & $\begin{array}{c}\text { Present adjustment required } \\
\text { Content }\end{array}$ & $\begin{array}{c}\text { Sand in total } \\
\text { aggregate }\end{array}$ \\
\hline $\begin{array}{c}\text { For decrease in } \\
\text { W/C ratio }\end{array}$ & 0 & -3.0 \\
\hline $\begin{array}{c}\text { For increase in } \\
\text { compaction factor }\end{array}$ & +3 & 0 \\
\hline For sand & 0 & -1.5 \\
\hline Total & 3 & -4.5 \\
\hline
\end{tabular}

Water content per cubic on concrete $=186 \mathrm{~kg}$

Sand constant as percentage of total aggregate $=35 \%$

Therefore required sand content as percentage of total aggregate by absolute volume

$=35-3.0$

$=32.0 \%$

Required water content $=186+3$

$=189 \mathrm{l} / \mathrm{m} 3$

$=189 \mathrm{l} / \mathrm{m} 3$ (approximately)
Determination of cement content

$\mathrm{W} / \mathrm{C}$ ratio $=0.45$

Water $=189$

$\mathrm{C}=189=436 \mathrm{~kg} / \mathrm{m} 3$

0.45

Determination of coarse and fine aggregate concrete:

$\mathrm{V}=(\mathrm{W}+\mathrm{C} / \mathrm{S}+\mathrm{l} / \mathrm{p} \mathrm{fa} / \mathrm{sfa}) \times 1 / 1000$

$0.99=(189+(420 / 3.10)+(1 / 0.305) *(\mathrm{fa} / 2.65) *(1 / 1000))$

$=189+135.48+1.180 \mathrm{f}$

$\mathrm{Fa}=654 \mathrm{~kg} / \mathrm{m} 3$

$\mathrm{Ca}=1-\mathrm{p} \times \mathrm{Fa} \times \mathrm{Sca}$

P Sfa

$\mathrm{Ca}=1-0.32 / 0.32 \times 530 \times 2.68 / 2.65$

$=2.125 \times 564 \times 1.011$

$=1309 \mathrm{~kg} / \mathrm{m} 3$

\section{PROPORTION}

Table 4.2: Mix Proportion

\begin{tabular}{|c|c|c|c|}
\hline Water & Cement & Fine aggregate & Coarse aggregate \\
\hline $\mathbf{1 8 9}$ & 436 & 654 & 1309 \\
\hline $\mathbf{0 . 4 5}$ & 1 & 1.26 & 2.88 \\
\hline
\end{tabular}

\begin{tabular}{|c|c|c|c|c|c|c|c|}
\hline \multirow[t]{3}{*}{ S.no } & \multirow[t]{3}{*}{ Mix id } & \multirow{3}{*}{$\begin{array}{l}\text { Ce-Ment } \\
(\mathrm{kg} / \mathrm{m} 3)\end{array}$} & \multirow{3}{*}{$\begin{array}{l}\text { F.Agg. } \\
\text { (kg/m3) }\end{array}$} & \multicolumn{2}{|c|}{ C. Agg. } & \multirow{2}{*}{$\begin{array}{l}\% \text { Re- } \\
\text { placement }\end{array}$} & \multirow[t]{2}{*}{$w / c$} \\
\hline & & & & \multirow{2}{*}{$\begin{array}{l}\text { Gravel- } \\
(\mathrm{kg} / \mathrm{m} 3)\end{array}$} & \multirow[t]{2}{*}{ Ruber } & & \\
\hline & & & & & & & \\
\hline \multirow[t]{2}{*}{1} & $\mathrm{PC}$ & 436 & 654 & 1309 & & & 0.4 \\
\hline & & & & & & & 5 \\
\hline \multirow[t]{2}{*}{2} & & 436 & 654 & 1243 & 66 & 5 & 0.4 \\
\hline & UTR-5 & & & & & & 5 \\
\hline 3 & $\begin{array}{l}\text { UTR- } \\
10\end{array}$ & 436 & 654 & 1178 & 131 & 10 & 0.4 \\
\hline
\end{tabular}


International Journal of Trend in Scientific Research and Development (IJTSRD) ISSN: 2456-6470

\begin{tabular}{|c|c|c|c|c|c|c|c|}
\hline & & & & & & & 5 \\
\hline \multirow[t]{2}{*}{4} & $\begin{array}{l}\text { UTR- } \\
15\end{array}$ & 436 & 654 & 1112 & 196 & 15 & 0.4 \\
\hline & & & & & & & 5 \\
\hline \multirow[t]{2}{*}{5} & NTR-5 & 436 & 654 & 1243 & 66 & 5 & 0.4 \\
\hline & & & & & & & 5 \\
\hline \multirow[t]{2}{*}{6} & $\begin{array}{l}\text { NTR- } \\
10\end{array}$ & 436 & 654 & 1178 & 131 & 10 & 0.4 \\
\hline & & & & & & & 5 \\
\hline \multirow[t]{2}{*}{7} & $\begin{array}{l}\text { NTR- } \\
15\end{array}$ & 436 & 654 & 1112 & 196 & 15 & 0.4 \\
\hline & & & & & & & 5 \\
\hline \multirow[t]{2}{*}{8} & CTR-5 & 436 & 654 & 1243 & 66 & 5 & 0.4 \\
\hline & & & & & & & 5 \\
\hline \multirow[t]{2}{*}{9} & $\begin{array}{l}\text { CTR- } \\
10 \\
\end{array}$ & 436 & 654 & 1178 & 131 & 10 & 0.4 \\
\hline & & & & & & & 5 \\
\hline \multirow[t]{2}{*}{10} & $\begin{array}{l}\text { CTR- } \\
15\end{array}$ & 436 & 654 & 1112 & 196 & 15 & 0.4 \\
\hline & & & & & & & 5 \\
\hline
\end{tabular}

Where;

UTR-5 represents untreated 5\% rubber.

NTR-5 represents sodium hydroxide treated rubber.

CTR-5 represents cement treated rubber.

PC represents plain concrete.

\subsection{Curing:}

Curing is an integral part of the process of working with concrete. After the concrete is in place, it begins to dry as the moisture in it evaporates. The more slowly this process happens, the stronger the resulting concrete is. Curing methods help to slow down the drying of the concrete, resulting in a stronger bond and more durable structure.

Curing is thus the process in which the mortar is protected from loss of moisture and kept within a reasonable temperature range. After 24 hours the cubes and beams were removed from the moulds and kept for curing in buckets, plastic jars and in curing tank. The curing was done for a period of 7 days and 28 days in case of 7 day and 28 day tests respectively.

\subsection{Testing:}

The testing program includes a variety of tests that address workability of the fresh concrete and compressive and flexural strengths of the samples. The compressive strength was checked using compression testing machine in which the samples were tested for 7 days and 28 days.The UTM (universal testing machine) was used to check the flexural strength of samples 28 days. Slump test was performed for each mix design of concrete to check the workability of concrete on every partial replacement of coarse and fine aggregates.Another test i.e. tensile split strength test was done using

CTM(compression testing machine) 


\section{RESULT AND INTERPRETATION}

The results show the variation in Compressive strengths, Flexural strengths,split tensile strength of various mixes in which the coarse aggregates are replaced by various percentages of tyre rubber. (Refer Table 4.1). The results also show the variation in Compressive strength.

\subsection{Workability test results for varying rubber content as aggregate:}

Table 5.1: workability results

\begin{tabular}{|l|l|l|l|}
\hline & Sample. & Slump $(\mathbf{m m})$. & $\begin{array}{l}\text { \% age reduction of } \\
\text { slump. }\end{array}$ \\
\hline & & & \\
\hline & PC & 50 & 0 \\
\hline & UTR-5 & 47 & 6 \\
\hline & UTR-10 & & \\
\hline & & 45 & 10 \\
\hline & UTR-15 & 43 & 14 \\
\hline & & & \\
\hline & NTR-5 & 48 & 4 \\
\hline & & & 12 \\
\hline & NTR-10 & 44 & \\
\hline & & & 20 \\
\hline & NTR-15 & 40 & 10 \\
\hline & & & \\
\hline & CTR-5 & 45 & 30 \\
\hline & CTR-10 & 42 & \\
\hline & CTR-15 & 35 & \\
\hline
\end{tabular}

\subsection{Compression Test:}

7 days Compressive strength concrete with 5,10 and $15 \%$ replacements of coarse agg. by tyre rubber.
Table 5.2: 7 days compressive strength of cubes

\begin{tabular}{|l|l|}
\hline \multicolumn{1}{|c|}{ Sample } & Strength(N/mm2) \\
\hline PC & 19.11 \\
\hline UTR-5 & 13.87 \\
\hline UTR-10 & 16.44 \\
\hline UTR-15 & 15.6 \\
\hline NTR-5 & 16.4 \\
\hline NTR-10 & 17.7 \\
\hline NTR-15 & 11.11 \\
\hline CTR-5 & 15.6 \\
\hline CTR-10 & 15.11 \\
\hline CTR-15 & 17.33 \\
\hline
\end{tabular}


International Journal of Trend in Scientific Research and Development (IJTSRD) ISSN: 2456-6470 28 days Compressive strength concrete with 5, 10, 15

$\%$ replacements of coarse agg. by tyre rubber.

\subsection{Split Tensile Strength Test:}

Table 5.3: 28 days compressive strength of cubes

\begin{tabular}{|c|c|}
\hline Samples & Strength(N/mm2) \\
\hline PC & 8.1 \\
\hline UTR-5 & 7.95 \\
\hline UTR-10 & 6.9 \\
\hline UTR-15 & 7.4 \\
\hline NTR-5 & 9.3 \\
\hline NTR-10 & 8.75 \\
\hline NTR-15 & 7.51 \\
\hline CTR-5 & 9.25 \\
\hline CTR-10 & 8.51 \\
\hline CTR-15 & 8 \\
\hline
\end{tabular}

When load is applied along the generatrix, an element on the vertical diameter of the cylinder is subjected to horizontal stress of magnitude ;

Stress $=\frac{2 p}{\pi L D}\left(\mathrm{~N} / \mathrm{mm}^{2}\right)$

Table 5.6: 28 days split tensile strength.

Table 5.5: Load vs displacement during flexure

\begin{tabular}{|l|c|c|}
\hline Sample & $\begin{array}{c}\text { Ultimate } \\
\text { load(KN) }\end{array}$ & Displacement(mm) \\
\hline PC & 16.2 & 0.96 \\
\hline UTR-5 & 15.9 & 1.12 \\
\hline UTR-10 & 13.8 & 1.1 \\
\hline UTR-15 & 14.8 & 0.8 \\
\hline NTR-5 & 18.6 & 1.3 \\
\hline NTR-10 & 17.5 & 1.5 \\
\hline NTR-15 & 15.02 & 1.38 \\
\hline CTR-5 & 18.5 & 1.6 \\
\hline CTR-10 & 17.02 & 1.45 \\
\hline CTR-15 & 16 & 1.3 \\
\hline
\end{tabular}

\begin{tabular}{|c|c|}
\hline Sample & $\begin{array}{c}\text { Strength(N/mm } \\
\text { 2) }\end{array}$ \\
\hline PC & 2.38 \\
\hline UTR-5 & 2.1 \\
\hline UTR-10 & 1.9 \\
\hline UTR-15 & 1.6 \\
\hline NTR-5 & 3.82 \\
\hline NTR-10 & 5.72 \\
\hline NTR-15 & 6.36 \\
\hline CTR-5 & 4.76 \\
\hline CTR-10 & 4.28 \\
\hline CTR-15 & 4.076 \\
\hline
\end{tabular}

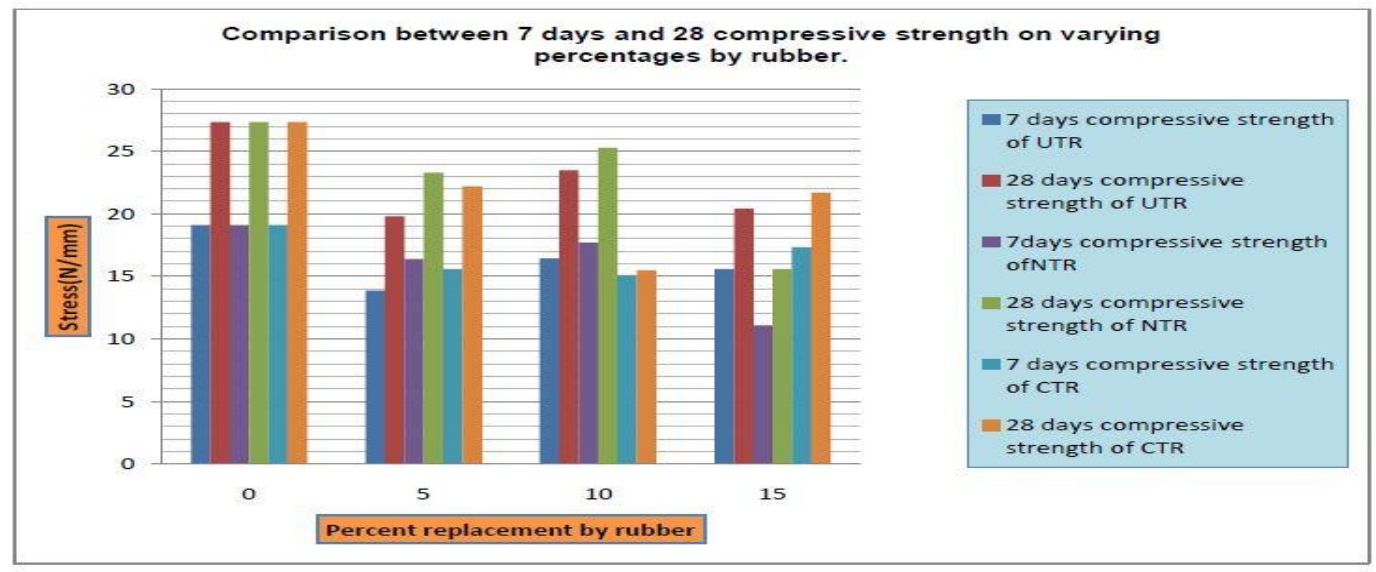



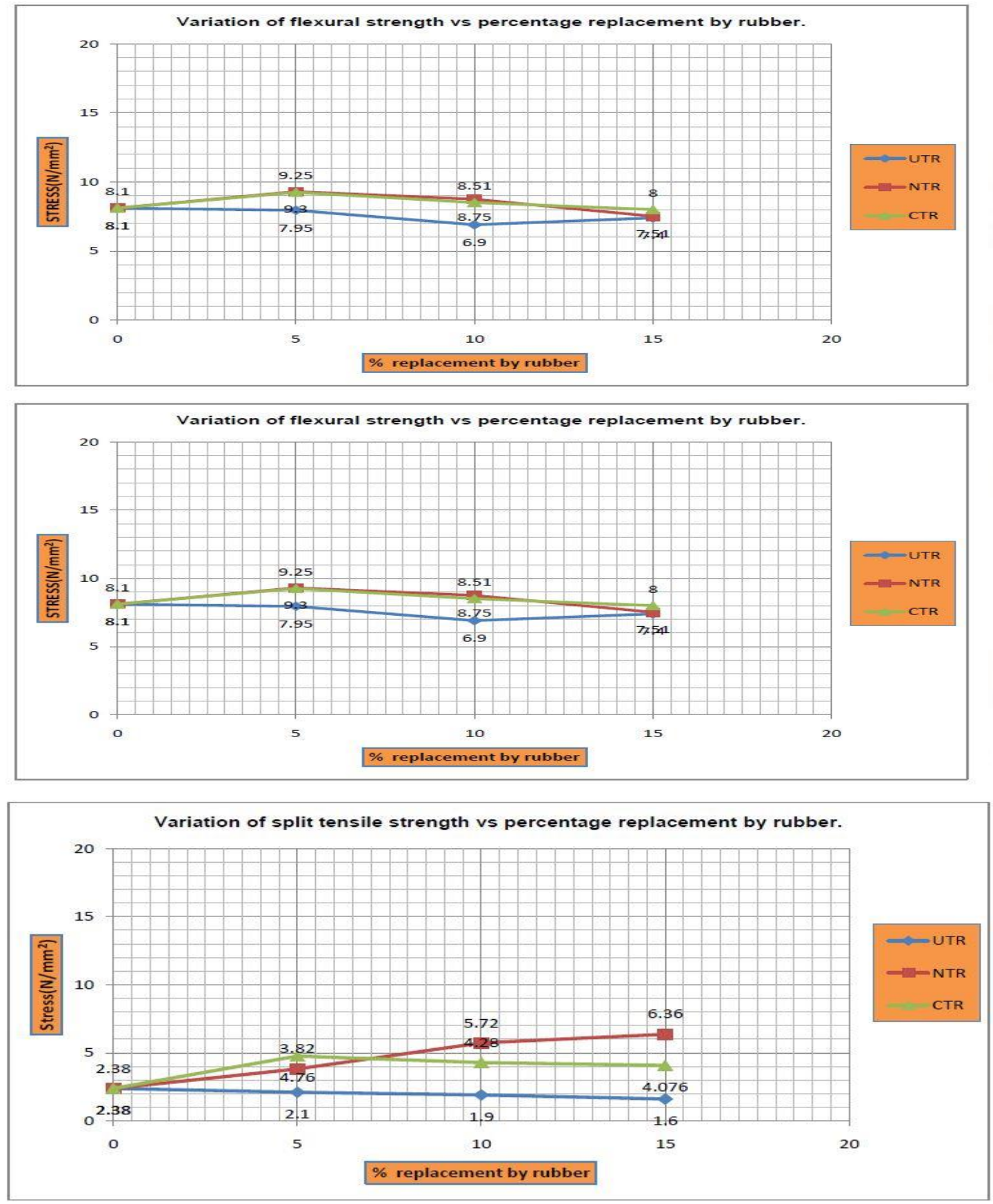

\section{CONCLUSION AND RECOMMENDATIONS}

The purpose of this study was to determine if waste materials such as rubber enhances the characteristic properties of concrete. The data presented in this project shows that there is great potential for the utilization of waste rubber. It is considered that the waste rubber form would provide much greater opportunities for value adding and cost recovery, as it could be used as a replacement for expensive materials such as coarse aggregate.
In this project, the performance of concrete made rubber aggregates was studied. The following conclusions were drawn:

1. Fresh concrete properties such as Unit weight and Slump decreased with the higher replacement levels of rubber.

2. Increase in rubber content decreased the compressive strength of the concrete significantly.

3. There is a great potential for rubber to be used in the concrete, thus saves area from becoming as landfill and is thus eco-friendly with environment.

4. The combined action of air and rubber creates a discreet thermal insulation that pre-vents the 
International Journal of Trend in Scientific Research and Development (IJTSRD) ISSN: 2456-6470

transport of heat. If we analyze such properties in relation to density in the hardened state, we can note an increase of the thermal conductivity with the density increasing, the increase of density corresponds to a more compact structure, so to a reduction of its porosity.

5. In reference to the test concerning the resistance of rubber-crete to Sulphatic attack, it is evident that, all the blends have lower compressive strength compared to the normal condition; consequently they are all vulnerable to attack by sulphate ions.

6. During the tests it was noted that as the percentage amount of shredded tyres in-creased, the amount of energy required for casting specimens increased substantially, because of the reduction of workability in the concrete.

7. The purpose of this study was to determine if a waste material like worn out tyres enhance the characteristic properties of concrete.The data presented in this project shows that there is great potential for the utilization of tyres as aggregates. It is considered that used tyres would provide much greater opportunities for valueadding and cost recovery, as it could be used as a replacement for more expensive material such as rock aggregate.

8. The flexibility of the rubber tyres is far better than natural aggregates,thus it is very useful in the formation of road pavements and flexible slabs.

Thus we can conclude that Reduced compressive strength of concrete due to the inclusion of rubber aggregates do limit its use in some structural applications, but it has few desirable characteristics such as lower density, higher impact and tough-ness resistance, enhanced ductility, and better sound insulation etc. These proper-ties can be advantageous to some construction applications. It is also possible to make relatively high-strength rubber concrete using $\mathrm{NaoH}$ and cement paste treatment to rubber aggregates, which gives better bonding characteristics to rubber and significantly improves the performance of rubber-crete.

\subsection{Recommendation}

\section{Workability:}

The workability of concrete due to partial replacement of coarse aggregate by untreated rubber decreases the workability with respect to standard. The workability decreases to small extent due to addition of untreated rubber. When treatment was given to rubber aggregates there was a huge decrease in workability.
Thus we came to know that due to use of rubber aggregate as partial replacement of coarse aggregate workability can be in-creased by adding certain plasticizers.

\section{Compressive Strength:}

There is decrease in compressive strength of concrete on $\%$ replacement of coarse aggregate by rubber aggregates. The compressive strength of NTR-10 is found to be highest among all the replaced mixes, which is comparably same as plain concrete .so we recommend NTR-10 to be the best option as compared to other replacement mixes.

\section{Split Tensile Strength:}

Split tensile strength of rubber concrete also increases in both the treatments. However, maximum tensile strength was found to be in case of sodium hydroxide treatment at $15 \%$ replacement of coarse aggregate by rubber aggregate. In case of cement paste treatment, maximum split tensile strength was found to be at $5 \%$ replacement by rubber.

\section{Flexural Strength:}

The 28 days flexure strength of NTR- 5 is found to be highest among all replacement mixes. Untreated rubber concrete showed decrease in flexure strength while as treated rubber showed varying trend. In $\mathrm{NaOH}$ treatment of rubber, the maximum flexure strength is found to be at $5 \%$ replacement while as minimum flexure strength is found to be at $15 \%$. In case of cement treatment, the maximum flexure strength is found to be at $5 \%$ replacement and minimum at $15 \%$ replacement. Hence, there is an overall increase in flexural strength of concrete at $5 \%$ replacement of coarse aggregates by both sodium hydroxides treated and cement treated rubber.

\section{Flexibility:}

On performing flexural tests, we came to know that due to incorporation of rubber in con-crete, it gained flexibility and was found to be maximum for NTR-10 (Ref. Table 4.9). So it can be used as a foundation material in earthquake areas due to flexibility and dampness as well.

\section{REFERENCES}

1) Gintautas S., Audrius G. and Benjaminas C., Deformation Properties of Concrete With Rubber 
International Journal of Trend in Scientific Research and Development (IJTSRD) ISSN: 2456-6470

Waste Additives, Lithuania: Kaunas University of Technology, 2007.

2) Malek K. Batayneh a, Iqbal Marie b, Ibrahim Asi Promoting the use of crumb rubber concrete in developing countries, Science Direct(2008).

3) Parveen, Sachin Dass, and Ankit Sharma. "Rubberized Concrete: Needs of Good Environment (Overview)." International Journal of Emerging Technology and Advanced Engineering (2013).

4) Ganjian, E., Khorami, M., Maghsoudi, A. K. (2008). Scrap-tyrerubber replacement for aggregate and filler in concrete, Construction and Building Materials.

5) Akinwonmi, Ademola Samuel, Seckley, Emmanuel, Department of Mechanical Engineering University of Mines, Mechanical Strength Of Concrete With Crumb And Shredded Tyre As Aggregate Replacement, IJERA (2013).

6) N. J. Azmi, B. S. Mohammed, H. M. A. AlMattarneh, Engineering Properties of Con-crete Containing Recycled Tyre Rubber, ICCBT(2008). 